\title{
Wireless Data Communication Techniques to Coordinate Distributed Rooftop PVs in Unbalanced Three-phase Feeder
}

\author{
Rachmawati, Anita Fauziah, Nelly Safitri ${ }^{\star}$ \\ Politeknik Negeri Lhokseumawe \\ JI. Banda Aceh-Medan Km. 280,3 Buketrata Lhokseumawe 24301 P.O. Box 90 \\ *Corresponding author, e-mail: nellysafitri@pnl.ac.id
}

\begin{abstract}
A necessity of the availability of communication network to provide data transfer amongst the coordinated single-phase rooftop photovoltaic (PV) in unbalanced three-phase low voltage (LV) feeder is essential since fetching data within the sensor of each PV unit requires real-time measurement and reliable data exchange within smart grid (SG), loads and other PV units. The main objective of this paper is to model the popular Wi-Fi, WiMax and ZigBee wireless data communication techniques into algorithms using numerical analysis. Those communication technologies have low cost and low power consumption. The benefits and drawbacks of those considered wireless data communications are shown as the required data that transferred and appropriate coding is also proposed. The number of transmitted symbols and the processing time delay of the proposed data coding are numerically analyzed, the results indicated that the $100 \%$ penetration level of $P V$ that resulted higher injected reactive power back into the networks is able to be overcome since the coordinated PVs along the feeder is communicating to lower the unbalanced voltage profile.
\end{abstract}

Keywords: rooftop PVs, LV feeder, Wi-Fi, Wi-max, ZigBee, numerical analysis

Copyright (C 2018 Universitas Ahmad Dahlan. All rights reserved.

\section{Introduction}

Installing random rated and located single-phase rooftop photovoltaic (PVs) in a certain neighborhood is leading to a substantial amount of electric energy generation in the form of distributed generators (DGs) within the electric networks. Their integration into the electric networks will cause several settlements, by reducing the network expansion costs, minimizing the power losses in long feeders and increasing the reliability of the network. They may also be accommodating to achieve faster recovery following a fault in the network [1].

As PVs coordinated in the LV feeder, the unequal loadings lead to an unbalanced network. Communication and intelligent system is required to support the power distribution system due to reducing voltage unbalance. In addition, it is expected that in the future all PV system in either grid-tied mode or off-grid mode will be totally computerized. The computerization system includes fetching data from sensors, passing the data to controllers and passing the control commands to the actuators [2].

The wireless technologies have fewer installation costs compared to the wired technologies and are more suitable for remote areas while being more flexible for the future expansions. The most popular wireless technologies that are used in power distribution system are Wi-Fi [3], Wi-Max [4] and ZigBee [5-6]. The required communication technology along the LV feeder is for covering the scattered location of the single-phase PV units, and handling a numerous and massive number of the sensors/meters/actuators. A comparison of different wireless technologies that can be considered for smart grid (SG) application is presented in Table 1.

In order to improve the imbalanced system, which mentioned earlier, this paper discusses the integration of communication-based and intelligent voltage profile regulating, which is discussed in [7] by using Wi-Fi, Wi-Max, and ZigBee, respectively, and modeling them in certain coding as numerical analysis to mitigate the advantages and disadvantages of their techniques to support the improvement of voltage profile and reduce voltage imbalance. 
The rest of the paper is arranged as follow, section 2 is discussed the three considered wireless data communication technologies, section 3 is discussed the proposed system, section 4 is described the simulation of results of the modeling systems, and finally section 5 is concluded the proposed system by presented the benefits and drawbacks of each proposed technique.

\section{Research Method}

\subsection{IEEE 802.11 (Wi-Fi)}

Wi-Fi stands for Wireless Fidelity. It is the most popular among the wireless standards developed by Wi-Fi Alliance under the IEEE 802.11 standards. The Physical Layer and the MAC layer of the Wi-Fi Technology are governed by the IEEE 802.11 standards. The IEEE 802.11 is a family of standards. The most popular among these versions are IEEE $802.11 \mathrm{~b}$ and IEEE 802.11g. The latest release is the IEEE 802.11n.

IEEE $802.11 \mathrm{~b}$ allows working in the ISM band at $2.4 \mathrm{GHz}$. It employs direct sequence spread spectrum (DSSS) modulation technique with data rates reaching up to $11 \mathrm{Mbps}$ for indoor environment and up to $1 \mathrm{Mbps}$ for outdoor environments. The indoor range is around 30$40 \mathrm{~m}$ while the outdoor range is around $90-100 \mathrm{~m}$ [3]. IEEE $802.11 \mathrm{~g}$ allows working at the same ISM band frequency of $2.4 \mathrm{GHz}$. It uses orthogonal frequency division multiplexing technique (OFDM) with data rates up to $54 \mathrm{Mbps}$. It is also compatible with IEEE $802.11 \mathrm{~b}$ standard devices. IEEE $802.11 \mathrm{~b}$ is the most commonly used standard amongst others. Wi-Fi provides robust performance in a shared spectrum and noisy of radio frequency (RF) channel environments. It supports all IP based protocols. A wide range of data rates is supported along with point-to-point and point-to-multipoint communications. Security features for secure and authentic data communication are also implemented, making it a strong contender for communication technologies for SG [3]. Therefore, this communication technology is suitable to be used for coordinating the single-phase rooftop PVs along the considered LV feeder as seen in Figure 1.

\subsection{IEEE 802.16 (Wi-Max)}

Wi-Max stands for Worldwide Interoperability for Microwave Access. This communication technology developed under the IEEE 802.16 standards for wireless broadband. Among the IEEE 802.16 standards, the most used standard is the IEEE 802.16e 2005. The IEEE 802.16 specifies the Physical and MAC layer for the Wi-Max technology. The Physical layer involves OFDMA with other features including multi-input-multi-output (MIMO) based antenna systems used in order to provide the non-line of sight capability.

Wi-Max technology uses two frequency bands, one for the line of sight (11-66 GHz) and other for the non-line-of-sight operation $(2-11 \mathrm{GHz})$. Wi-Max involves data encryption standard (DES) and advances encryption standard (AES) encryption techniques for secure and reliable data communication [8]. These security mechanisms are implemented at the MAC layer. MAC layer also incorporates power saving techniques such as sleep mode, idle mode, etc. WiMax is specifically designed for point-to-multipoint communications for both fixed and mobile applications; with data rates, up to $70 \mathrm{Mbps}$ over a distance of $50 \mathrm{~km}$ [9]. Therefore, this communication technology is more suitable for MV feeder with coordinated single-/three-phase rooftop PVs, whereas the load characteristics are varied.

\subsection{IEEE 802.15.4 (ZigBee)}

ZigBee is a wireless networking standard targeted at monitoring, control, and building and home automation [10-11]. ZigBee is designed to interconnect autonomous sensors and actuators to control units with an emphasis on low power consumption. It is a specification based on the IEEE 802.15.4 standard [12-13], extending that definition by developing new additional higher layers.

There are two different types of ZigBee device. The ZigBee coordinator is a full function device (FFD) that coordinates the network and forms its root, making a bridge with other networks, managing the network security and its security keys and also being able to store information about the network. The ZigBee router is an FFD that can have sensors and actuators but its capacity enables it to relay messages from other nodes, acting as a router. The ZigBee end device is a reduced function device (RFD) that can be connected to sensors and 
actuators and can be asleep most of the time to extend the battery life. It has reduced processing capacity, which means that it is cheaper to produce but it cannot relay messages. By the view of the IEEE 802.15.4 network topologies in the ZigBee standard, in a star topology, the network is controlled by one single device. In mesh and tree topologies the ZigBee coordinator is responsible for starting a new network when appropriate and assigning addresses to newly associated devices but the network may be extended through the use of ZigBee routers.

Table 1. Comparison of different wireless technologies applicable for grid-tied PV system

\begin{tabular}{|c|c|c|c|c|c|c|c|c|}
\hline Technology & Range & Data Rate & Frequency & Routing & Security & Suitable for & Modulation & Installation Cost \\
\hline $\mathrm{Wi}-\mathrm{Fi}$ & $100 \mathrm{~m}$ & 54Mbps & $2.4 \mathrm{GHz}$ & $\begin{array}{l}\text { More than } \\
70 \\
\text { Protocols }\end{array}$ & WPA & Backbone & $\begin{array}{l}\text { QPSK, } \\
\text { BPSK, } \\
\text { 16/64QAM }\end{array}$ & Moderate \\
\hline WiMax & $\begin{array}{l}\text { Several } \\
\mathrm{km}\end{array}$ & 30-40Mbps & $\begin{array}{l}\text { 2.3, } 2.5 \\
3.5 \mathrm{GHz}\end{array}$ & $\begin{array}{l}\text { AODV, DSR, } \\
\text { OLSR and } \\
\text { ZRP }\end{array}$ & $\begin{array}{l}\text { AES } \\
\text { and } \\
\text { 3DES }\end{array}$ & Backbone & $\begin{array}{l}\text { 16/64QAM, } \\
\text { OFDMA- } \\
\text { PHY }\end{array}$ & Moderate \\
\hline ZigBee & $\begin{array}{l}100- \\
150 \mathrm{~m}\end{array}$ & $250 \mathrm{kbps}$ & $\begin{array}{l}2.4 \mathrm{GHz}, \\
868, \\
915 \mathrm{MHz}\end{array}$ & $\begin{array}{l}\text { AODV, } \\
\text { HERA }\end{array}$ & AES & End devices & $\begin{array}{l}\text { OQPSK, } \\
\text { BPSK }\end{array}$ & Low \\
\hline
\end{tabular}

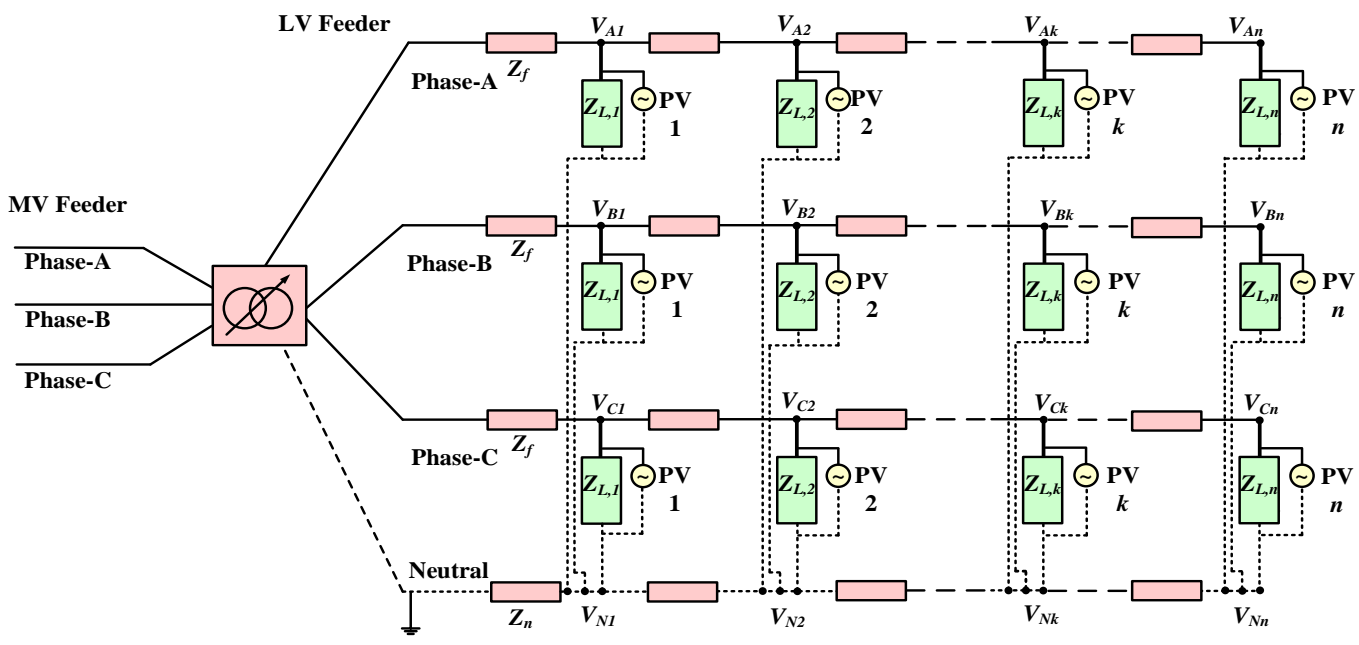

Figure 1. Network with PVs under consideration

The ZigBee network should be able to connect itself to other wireless or wired networks. The ZigBee alliance offers one solution for that need, called the ZigBee gateway. The ZigBee gateway provides high feature connectivity and allows a larger diversity of applications and devices to connect and control the ZigBee networks and their devices. It translates the ZigBee network and devices protocols to a variety of other formats that exist in the industrial, commercial and residential systems, providing an interface between the ZigBee and IP devices with an abstract interface that isolates the IP device from the ZigBee protocol and translates both commands and addresses between them. Therefore, this communication is suitable for coordinating single-phase rooftop PVs in the LV three-phase feeder as in Figure 1.

\section{Results and Analysis}

In this section, it is explained the results of research and at the same time is given the comprehensive discussion. It included the considered network, the modeling and analysis of the considered network, the considered wireless technologies and also the active and reactive power control of PVs in the LV feeder. 


\subsection{Network under consideration}

Let us consider an $11 \mathrm{kV}$ three-phase medium voltage feeder supplying a $380 \mathrm{~V}$ threephase four-wire low voltage residential feeder, as shown in Figure 1 [7]. The residential feeder is assumed to be unbalanced due to the distribution of loads and unequal distribution of singlephase rooftop PVs with different ratings. The configuration of the considered network is detailed in Table 2.

Table 2. Technical parameters of the simulated test network

\begin{tabular}{ll} 
Transformer & $11 / 0.415 \mathrm{kV}, 50 \mathrm{~Hz}, 150 \mathrm{kVA}, 50 \mathrm{~Hz}$, Dyn, $z=0.05 \mathrm{pu}$ \\
MV Feeder & $11 \mathrm{kV} \mathrm{L-Lrms}, 3-$ phase 3 -wire, $5 \mathrm{~km}, 1.08+j 0.0302 \Omega / \mathrm{km}$ \\
LV Feeder & 415 V L-Lrms, 3-phase 4-wire, $400 \mathrm{~m}, 0.452+j 0.270 \Omega / \mathrm{km}$ \\
\hline
\end{tabular}

\subsection{Network modelling and analysis}

An unbalanced sweep forward-backward load flow method is developed in MATLAB and used for the analysis of the three-phase four-wire radial network under consideration. The load flow calculates bus voltages along the feeder.

\subsection{Considered communication technologies}

As Wi-Fi, Wi-Max and ZigBee used for the developing technologies for PV communication in three-phase LV feeder, they are expected to coordinate the capability of single-phase rooftop PVs to mitigate the injected active and reactive power toward every phase along the feeder. Therefore, the regulation and reduction of the voltage profile of the unbalance three-phase LV feeder might achieve. In addition, Table 3 shows the comparison of the communication penetration among $\mathrm{Wi}-\mathrm{Fi}, \mathrm{Wi}-\mathrm{Max}$, and ZigBee in three-phase LV feeder with single-phase rooftop PVs. As the antennas that suitable for Wi-Fi communications, the discussion and analysis are detailed in reference [14] and [15].

Table 3. Penetration of the communication technologies

\begin{tabular}{|c|c|c|c|c|c|c|c|c|c|}
\hline \multirow{2}{*}{$\begin{array}{l}\text { Communication } \\
\text { Technologies }\end{array}$} & \multicolumn{2}{|c|}{ Generation } & \multicolumn{3}{|c|}{$\begin{array}{c}\text { Distribution } \\
\text { Substation } \text { Distribution Fquinment }\end{array}$} & \multicolumn{4}{|c|}{ Consumer } \\
\hline & Conventional & $\begin{array}{c}\text { Distributed } \\
\text { Renewable } \\
\text { \& Energy- } \\
\text { based }\end{array}$ & $\begin{array}{c}\text { Substation } \\
\text { Automation } \\
\& \\
\text { Protection }\end{array}$ & $\begin{array}{l}\text { Distribution } \\
\text { Line \& } \\
\text { Monitoring }\end{array}$ & $\begin{array}{c}\text { Equipment } \\
\text { Monitoring } \\
\& \\
\text { Protection }\end{array}$ & $\begin{array}{l}\text { Home } \\
\text { Automation } \\
\text { \& Control }\end{array}$ & $\begin{array}{l}\text { Industrial } \\
\text { Automation } \\
\text { \& Control }\end{array}$ & $\begin{array}{l}\text { Automatic } \\
\text { Metering } \\
\text { Reading }\end{array}$ & PEVs \\
\hline Wi-Fi & $\Delta$ & $\infty$ & $\checkmark$ & $\infty$ & $\checkmark$ & $\checkmark$ & $\boldsymbol{V}$ & $\checkmark$ & $\Delta$ \\
\hline Wi-Max & $\Delta$ & $\Delta$ & $\Delta$ & $\infty$ & $\infty$ & $\infty$ & $\infty$ & $\Delta$ & $\infty$ \\
\hline ZigBee & $\Delta$ & $\Delta$ & $\Delta$ & $\Delta$ & $\Delta$ & $\boldsymbol{\nu}$ & $\boldsymbol{\nu}$ & $\checkmark$ & $\Delta$ \\
\hline
\end{tabular}

Legends: $\Delta=$ ongoing research, some solution available but under testing

$\infty=$ not currently in use, solutions can be developed

$\boldsymbol{V}=$ in use, some developed solutions available

\subsection{Active and Reactive Power Control of PVs}

The consider the LV feeder of Figure 1 with 10 buses (nodes) where each node may have several single-phase PVs. $11 \mathrm{kV} / 380 \mathrm{~V}$ transformer supplies 30 houses, distributed equally among the phases is originated from [7]. The PV inverters currently operate in constant output power mode. Under such conditions, they only inject current with unity power factor and do not affect the voltage at their point of common coupling. If the inverter is operated in voltage control mode, each PV can correct its own PCC voltage to a desired value by injecting or absorbing the required amount of reactive power $\left(Q_{P V, r e f}\right)$. To minimize the difference between the PCC voltage $\left(V_{P C C}\right)$ with its reference value $\left(V_{P C C}\right.$,ref $)$, each $P V$ inverter needs to exchange reactive power with the feeder to keep the voltage of its output equal to the desired value based on the droop control strategy as

$$
Q_{P V, r e f}=m\left(V_{P C C, r e f}-V_{P C C}\right)
$$

where $m$ is a coefficient and will be assigned by the reactive power-voltage $(Q-V)$ droop controller. The $\mathrm{Q}-\mathrm{V}$ droop controller improves the dynamic oscillations between the reactive 
power and the voltage variation in the system. The calculated $Q_{\mathrm{PV} \text {,ref }}$ must be within the inverter capacity as

$$
-\sqrt{S_{P V, \text { max }}^{2}-P_{P V}^{2}} \leq Q_{P V, \text { ref }} \leq \sqrt{S_{P V, \text { max }}^{2}-P_{P V}^{2}}
$$

where $S_{P V \text {,max }}$ is the maximum apparent power of the $P V$ inverter. If the required $Q_{P V \text {,ref }}$ is beyond its maximum injection or absorption capability, it runs on the maximum limits.

\subsection{Study case}

The simulation of the unbalanced three-phase LV load flow runs over a three-phase fourwire radial network as the test case. The performance evaluation of the discussed system under load and PV uncertainties and the network of Figure 1 is considered as the test case. The 1 to 5 kW PV cells are assumed to have an equivalent distribution. In this study, the availability of sunlight irradiance is assumed between 6 am and $6 \mathrm{pm}$ while the PVs generate their maximum output at $12 \mathrm{pm}$. The $100 \%$ PV penetration level is considered. Following that, the different PVs' penetration levels are also calculated.

The considered PV communication technology is Zigbee since it is the most suitable for this test case. As PVs along the feeder are communicating during the generation of their maximum output, the coordination of them provided the improvement of the reactive power and voltage profile of the system. As the results, the load profile of 30 houses from the simulation of the test case is demonstrated in time-domain in Figure 3. It can be seen that mostly the PVs' active power reach their maximum output at noon, over the 24 -hr period.

\section{Conclusion}

This paper has evaluated the performance of an intelligent and communication-based using Wi-Fi, Wi-Max, and ZigBee to regulate voltage profile of the LV three-phase feeder within the standard limit. It also defines proper reference voltages for the three phases of the network at each bus which will be utilized by the PV inverters and uses reactive power support and active power curtailment to regulate the point common couple voltage of each PV inverter to the desired reference value. Based on the considered test case, the coordinated of PVs along the three-phase feeder are well communicated since the output power and voltage profile of the system are successfully improved.

It can be seen that Wi-Fi and ZigBee based communication are easily available for home automation and automatic metering reading (AMR) purposes. The hot issue nowadays is to develop solutions for PEVs, which currently a major consumer of electricity in several developed countries. On one hand, Wi-Max is not very popular among researchers and therefore only AMR based activities are seen till now. On the other hand, ZigBee discovers the most positive response towards the home automation.

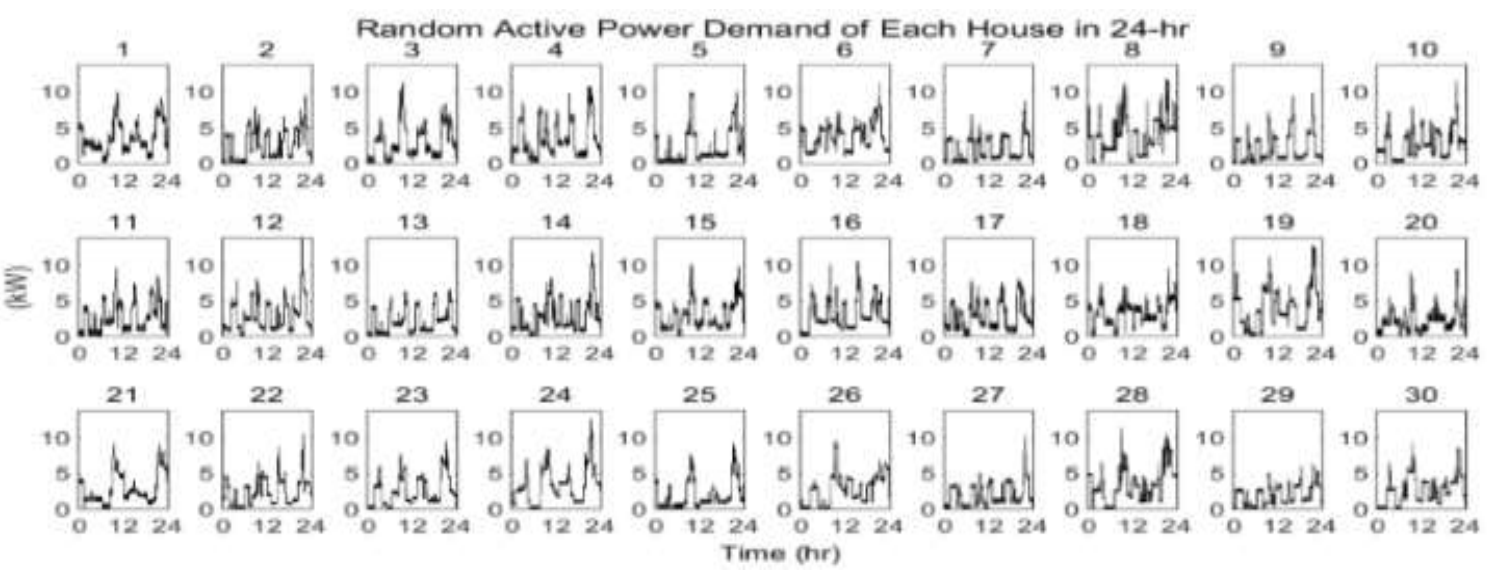

Figure 3. Considered random residential demand for 30 houses over a 24-hr period 


\section{References}

[1] RH Lasseter, P Paigi. Microgrid: a conceptual solution. 35th Annual Power Electronics Specialists Conference. 2004: 4285-4290.

[2] A Sendin. Communication Technologies, Networks, and Strategies for Practical Smart Grid Deployments: From Substations to Meters. in Communication and Networking in Smart Grids, 1st Edition. Y Xiao, Ed. New York: CRC Press. 2012: $241-275$.

[3] A Usman, SH Shami. Evolution of Communication Technologies for Smart Grid applications. Renew. Sustain. Energy Rev. 2013; 19: 191-199.

[4] A Cama, FG Montoya, J Gómez, JL De La Cruz, F Manzano- Agugliaro. Integration of communication technologies in sensor networks to monitor the Amazon environment. J. Clean. Prod. 2013; 59: 32-42.

[5] NC Batista, R Melício, JCO Matias, JPS Catalão. Photovoltaic and wind energy systems monitoring and building/home energy management using ZigBee devices within a smart grid. Energy. 2013; 49: 306-315.

[6] NK Suryadevara, S Member, SC Mukhopadhyay, et al. WSN-Based Smart Sensors and Actuator for Power Management in Intelligent Buildings. IEEE/ASME Trans. Mechatronics. 2014; 99: 1-8.

[7] N Safitri, F Shahnia, MAS Masoum. Different techniques for simultaneously increasing the penetration level of rooftop PVs in residential LV networks and improving voltage profile. 6th IEEE PESAsia-Pacific Power and Energy Engineering Conference (APPEEC), Hong Kong. 2014: 1-5.

[8] C So-In, R Jain, A Tamimi. Scheduling in IEEE 802.16e mobile Wi-Max networks: key issues and a survey. IEEE Journal on Selected Areas in Communications. 2009; 27(1): 56-71.

[9] Wi-Max-Part M. I: A technical overview and performance evaluation. In: Wi-Max forum.

[10] R Walawalkar, S Fernands, N Thakur, NR Chevva. Evolution and current status of demand response (DR) in electricity markets. insights from PJM and NYISO. Energy. 2010; 35: 1553e60.

[11] LC Huang, HC Chang, CC Chen, CC Kuo. A ZigBee-based monitoring and protection system for building electrical safety. Energy Build. 2011; 43: 1418e26.

[12] Han DM, Lim JH. Smart home energy management system using IEEE 802.15.4 and ZigBee. IEEE Trans Consum Electron. 2010; 56: 1403e10.

[13] Bonifácio TG, Pantoni RP, Brandão D. SMAC multi-hop mesh routing protocol using IEEE 802.15.4. Comput Electr Eng. 2012; 38: 492e509.

[14] AF Morabito, AR Laganà, G Sorbello, T Isernia. Mask-constrained power synthesis of maximally sparse linear arrays through a compressive-sensing-driven strategy. Journal of Electromagnetic Waves and Applications. 2015; 29(10): 1384-1396.

[15] AF Morabito, AR Lagana, T Isernia. Isophoric array antennas with a low number of control points: a 'size tapered' solution. Progress in Electromagnetics Research Letters. 2013; 36: 121-131. 